\title{
AUGMENTED REALITY AND VIRTUAL REALITY IN RETAIL - A BIBLIOMETRIC ANALYSIS
}

\author{
Anasuya Bardhan 1 \\ ${ }^{1}$ Symbiosis Institute of Operations Management, Nasik,Symbiosis International (Deemed University), Pune, India
}

\begin{abstract}
Purpose - "Augmented and Virtual Reality" is a trend in retail that is lately catching a lot of attraction. These interactive technologies enhance the retail process by offering a better shopping experience and affects consumer's preference towards the retailers. Retailers need to align their business model to counteract the changing traffic patterns. This study will help in inferring trends, themes researched, identifying the prolific authors, researchers, and present the big picture.

Methodology - To understand the current research state, Biblioshiny and VOS viewer has been employed to conduct a quantitative study on research papers done in the field of AR/VR in retail during the period 1993-2020 from the "Web of Science core database".

Findings - (1) Increase in publication of papers in the past 27 years, divided into 2 parts: a low exploration period and developmental period. (2) The research covers 38 countries. With respect to the research volume, the top five countries being - (i) "China", (ii) "the United States", (iii) "the United Kingdom", (iv) "Germany", and (v) "South Korea". There has been a lot of collaboration between these countries, with maximum collaboration between the USA and China. (3) Virtual Reality, Retailing, Interactivity are amongst the trending keywords in this field in recent years. (4) The main research themes in area of AR/VR in retail mainly focuses on the research directions like - the adoption of the technology, impact on consumer behavior, and performance and user's information control.
\end{abstract}

An overview of present state of academic studies was generated by employing a knowledge-based map which recognises researcher collaboration networks. This study is riveting as it has rarely been examined in this in a new manner.

\section{Keywords:}

Retail, Augmented Reality, Technology, Virtual Reality, E-commerce, Customer Satisfaction, service, customer experience, Bibliometric

Article Received: 10 August 2020, Revised: 25 October 2020, Accepted: 18 November 2020

\section{Introduction}

The retail industry is amongst the vital sectors in the economy, with presently a market size of approximately 26 trillion US Dollars. (Statitsa,2020) The industry focusses on the sale of goods and services to consumers via different distribution channels. This makes the entire retail business customer-centric. Rapid technological advancements have increased the competitiveness and complexity in the retail sector. (Pantano et al., 2017). With the advancement of technology, the customers form impressions of the brand through the touchpoints.

Given the accelerating rate of change in the retail industry, the retailers must understand customer behavior and align their business model to counteract the changing traffic patterns by offering an appropriate value proposition. (Hopping, 2000). Tech giants like Apple, Microsoft, and Google have recently invested hugely in AR/VR technology (Cruz et al., 2019). As per (Grewal, 2017), "Augmented Reality is amongst the emerging technologies that will shape the retail's future."

Augmented and Virtual Reality (AR/VR) are interactive technologies which enhance the retail process by offering a better shopping experience and affects consumer's preference towards the retailers (Pantano, 2016). Virtual Reality creates a simulated environment by adding 3D virtual objects in the real world, that coexists along with the real world, and Augmented Reality enriches the physical world by adding virtual information to it, hence, enhances user's perception. (Azuma et al., 2001)

Researchers use different kinds of quantitative and qualitative literature review analysis to organize and understand previous findings. Amongst these, bibliometrics offers more factual and authentic analyses and possesses the capability to give a transparent, systematic, and logical review process 
which is based on the statistical measurement (Broadus, 1987). This helps in inferring trends, themes researched, identifying the prolific authors, researchers, and presents the big picture.

This paper uses a Bibliometric Analysis methodology on Augmented and Virtual Reality (AR/VR) technology in retail-based publications and Web of Science documents are selected from the for the period 1993-2020. An overview of present state of academic studies was generated by using a knowledge-based map which recognises researcher collaboration networks. The results are riveting as they have rarely been deliberated like this in a new manner. This paper is shaped in this manner: [1] Methodology [2] Analysis. [3] Discussion and conclusions.

\section{Methodology}

The approach in this paper is - Bibliometric analysis. For this method, "Web of Science" was chosen and selectively chose articles only from the "Web of Science Core Collection" database because of its good quality and technological database on several topics. The results show a lack of bibliometric research done on the AR/VR in retail. Hence, a broad and extensive outline of scientific analysis was obtained concerning this topic. The raw data provided the total citations (Bornmann \& Daniel, 2008), crucial for us to rank the journals. Ranking of a journal is useful as it helps to measure the quality of journals that have investigated the subject of "Augmented and Virtual reality" in a retail scenario (Smith, 1981). Also, the study aids in generating quantitative familiarity on this particular area (Albort-Morant \& Ribeiro-Soriano, 2016a). Considering the need to accommodate new challenges, the study shows the general line of retail-based study concerning dominant journals, papers, and authors. The main objective is to prompt the academic and business worlds on the significance of AR and VR in retail. This can result in an important determinant to create new approaches which could be chosen as a competitive edge for the retailer or companies in this field (Reeves Martin \& Deimler Mike, 2011)

\section{Database Selection}

For this paper, the database that has been considered is - "Web of Science (WoS)" for the period 1993-2020. Also, for the study, only the good quality articles were contemplated so selected only the ones which fall under the Web of
Science Core Collection. It was then further narrowed down to 173 articles that fall in the research area of Business Management. Documents in the English Language was only selected.

Biblioshiny and the visualization tool "VOS viewer" were employed, these gathered the keywords from the dataset and generated a cooccurrence matrix and others. Other bibliometric studies have been considered as well to develop the research. (Albort-Morant \& Ribeiro-Soriano, 2016b).

\section{Research Method}

For the analysis, the "VOS viewer" and "Biblioshiny" have been considered. Biblioshiny uses an $\mathrm{R}$ language shiny software package that encapsulates the core bibliometrix code and creates a online data analysis framework. It was developed by Massimo Aria (Aria \& Cuccurullo, 2017). To carry out the bibliometric analysis on biblioshiny, we installed it. The steps are as mentioned:

[1] Download - (latest) R-language program and Rstudio platform

[2] Install the same and open Rstudio.

[3] Type the following commands:

$>$ install.packages ("bibliometrix");

$>$ Library (bibliometrix)

$>$ biblioshiny()

This paper analyses and visualizes the research state and hotspots in the area of AR/VR in retail from various aspects. At last, it gives references and provides a suggestion for future retail. This study can be described as a prescriptive analysis that studies 173 documents of AR/VR technology in retail and aims to give a reference point for business practitioners as well as researchers. The paper includes sections: methodology, analysis, and conclusion.

\subsection{Documents Distribution}

Figure 1 shows the annual production of articles related to Augmented Reality/ Virtual Reality. There is limited production at the start, back in 1997 to the early 2000s. However, even with a slight fluctuation, it has been on an increasing 
trend and saw a spike increase in 2019. Given the limited number of publications, the paper has considered 2 time zones - 1997-2009 and 20102020. The period 1997-2009 is a less explored period. Before 2010, the rise in the publishedarticles was slow-moving, and also in between these years, the annual average published volume does not vary much. The study on AR/VR technology in retail was in beginning stage, implying the importance of Augmented and Virtual Reality was not much popular amidst the researchers. In case of the developmental period of 2010-2020, the number of articles published in this time rose gradually. Especially, after 2015, the production entered a stage of rapid development, with 2019 publications being maximum i.e., 40.

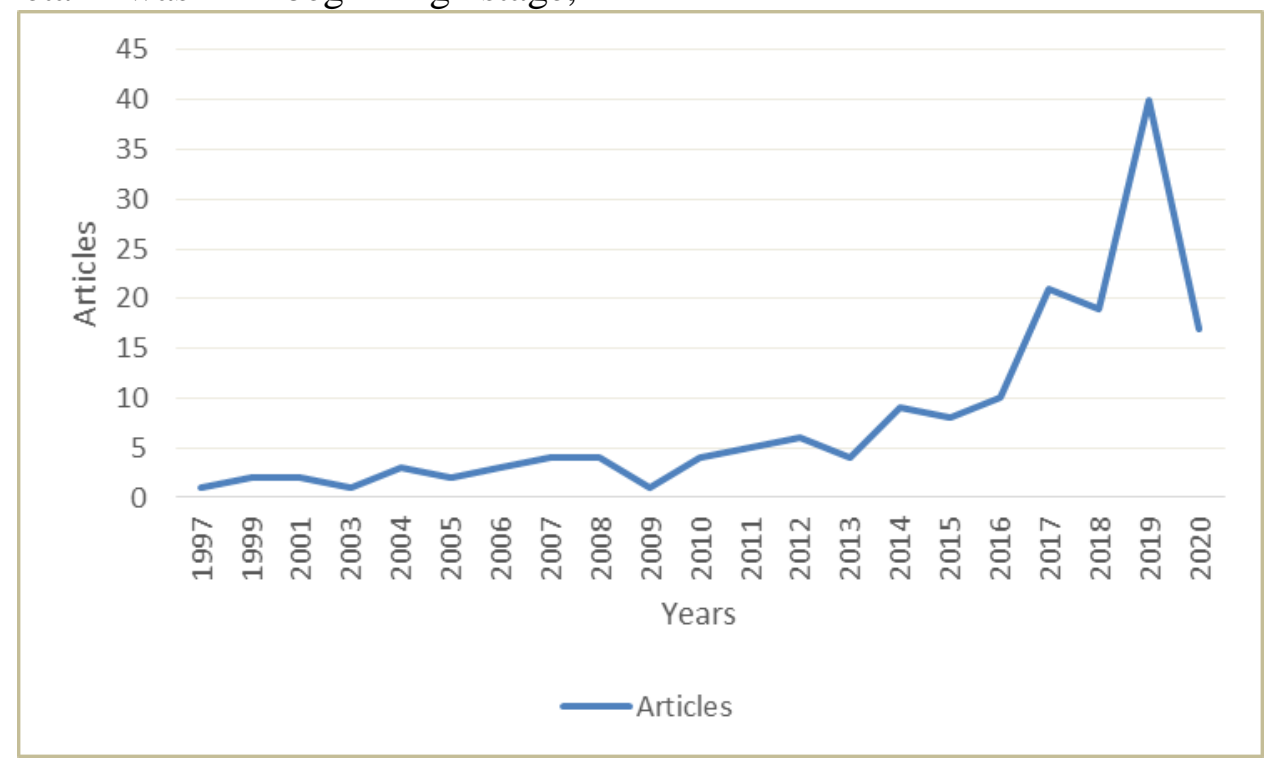

Fig 1: Articles published in 1990-2020.

\begin{tabular}{|l|l|l|}
\hline Paper & Total Citations & TC per Year \\
\hline SUH KS, 2005, MIS Q & 150 & 9.375 \\
\hline THAKUR R, 2014, INTERNET RES & 128 & 18.2857 \\
\hline OLSSON T, 2013, PERS UBIQUITOUS COMPUT & 104 & 13 \\
\hline STANDEN PJ, 2005, CYBERPSYCHOL BEHAV & 93 & 5.8125 \\
\hline BAUCUS DA, 1996, J BUS VENTUR & 79 & 3.16 \\
\hline JAVORNIK A, 2016, J RETAIL CONSUM SERV & 72 & 14.4 \\
\hline GROSS M, 2015, INT J RETAIL DISTRIB MANAG & 72 & 12 \\
\hline SUH KS, 2006, BEHAV INF TECHNOL & 67 & 4.4667 \\
\hline WEI LY, 2016, APPL SOFT COMPUT & 65 & 13 \\
\hline PONCIN I, 2014, J RETAIL CONSUM SERV & 62 & 8.8571 \\
\hline
\end{tabular}

Table 1: Most Cited Documents

By analyzing the data, it can be seen that (Suh \& Lee, 2005) paper has the highest total citations, and (Thakur \& Srivastava, 2014) has the highest total citations per year. (Suh \& Lee, 2005) studied the circumstances under which Virtual Reality enhances consumer's learning about products. The results show that the VR interface increases the overall learning of the consumer by offering interactivity and high-quality 3-D images of products. (Thakur \& Srivastava, 2014) studied model readiness and acceptance of varied determinants on the intention of mobile payments usage among customers using structural equation modelling.

\subsection{Analysis of Influential Journals}

The figure indicates that the "Journal of Retailing and Consumer Service" with the highest "Hindex", i.e., 9. implying there are a minimum of 9 articles in this journal that has atleast of 9 citations each. Computers in Human Behaviour and Journal of Retail \& Distribution Management follow in second and third place. This analysis helps 
researchers to know the scientific research production level in this field. (Nicolas et al., 2019) Source Impact

JOURNAL OF RETAILING AND CONSUMER SERVICES COMPUTERS IN HUMAN BEHAVIOR IIONAL JOURNAL OF RETAIL \\& DISTRIBUTION MANAGEMENT INTERNET RESEARCH JOURNAL OF BUSINESS RESEARCH CYBERPSYCHOLOGY \\& BEHAVIOR TECHNOLOGICAL FORECASTING AND SOCIAL CHANGE FRONTIERS IN PSYCHOLOGY

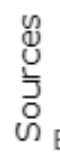
BEHAVIOUR \\& INFORMATION TECHNOLOGY JOURNAL OF RETAILING BUSINESS HORIZONS ( ELECTRONIC COMMERCE RESEARCH AND APPLICATIONS JOURNAL OF ENTERPRISE INFORMATION MANAGEMENT JOURNAL OF NEUROENGINEERING AND REHABILITATION JOURNAL OF THE ACADEMY OF MARKETING SCIENCE KNOWLEDGE-BASED SYSTEMS NEURAL COMPUTING \\& APPLICATIONS VIRTUAL REALITY IEEE ACCESS GMENTED REALITY FOR FOOD MARKETERS AND CONSUMERS

Fig 2: Source Impact

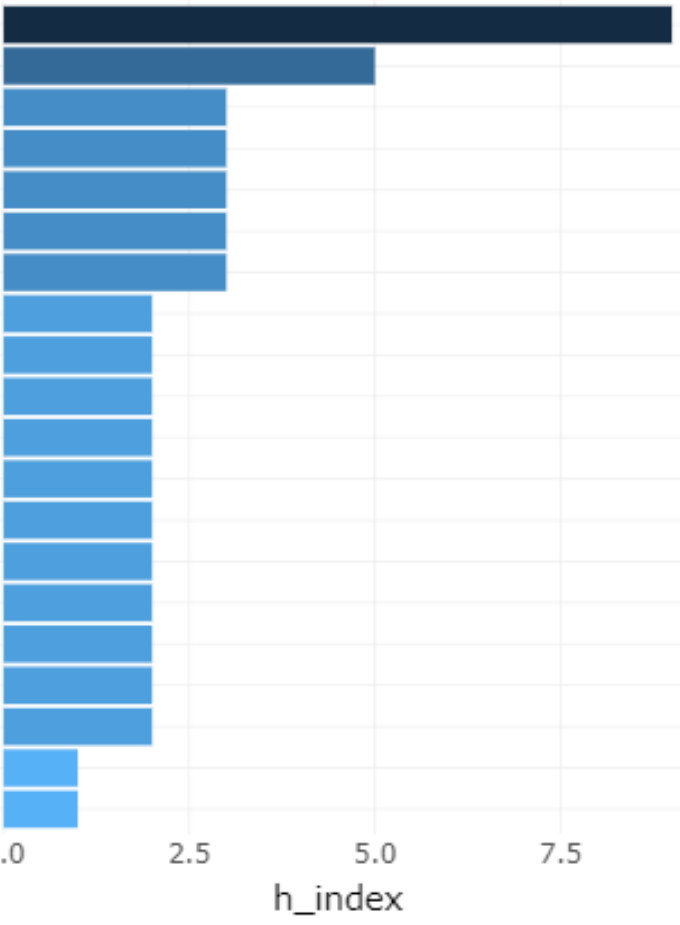

Brengman M, Brito Pq, and Chen S. Pantano E's "h-index", "g-index", and "total citation values" are 4,6,108 in succession. In below Figure 3, the size of the circle represents several documents and the color shade represents many citations. Pantano E has started publishing papers from 2012, with the "maximum number of published documents" as well as the "highest frequency of average
The data retrieved from search results involves 507 authors, among which 25 authors have one paper, 482 authors have authored in more than one paper. From the database as can be seen in Table 2, the top five authors Pantano E, Huang Tl, Baier $\mathrm{D}$, Pfeiffer J, Arli D, Balaji Ms, Bien Cg, citations per item" in 2018.

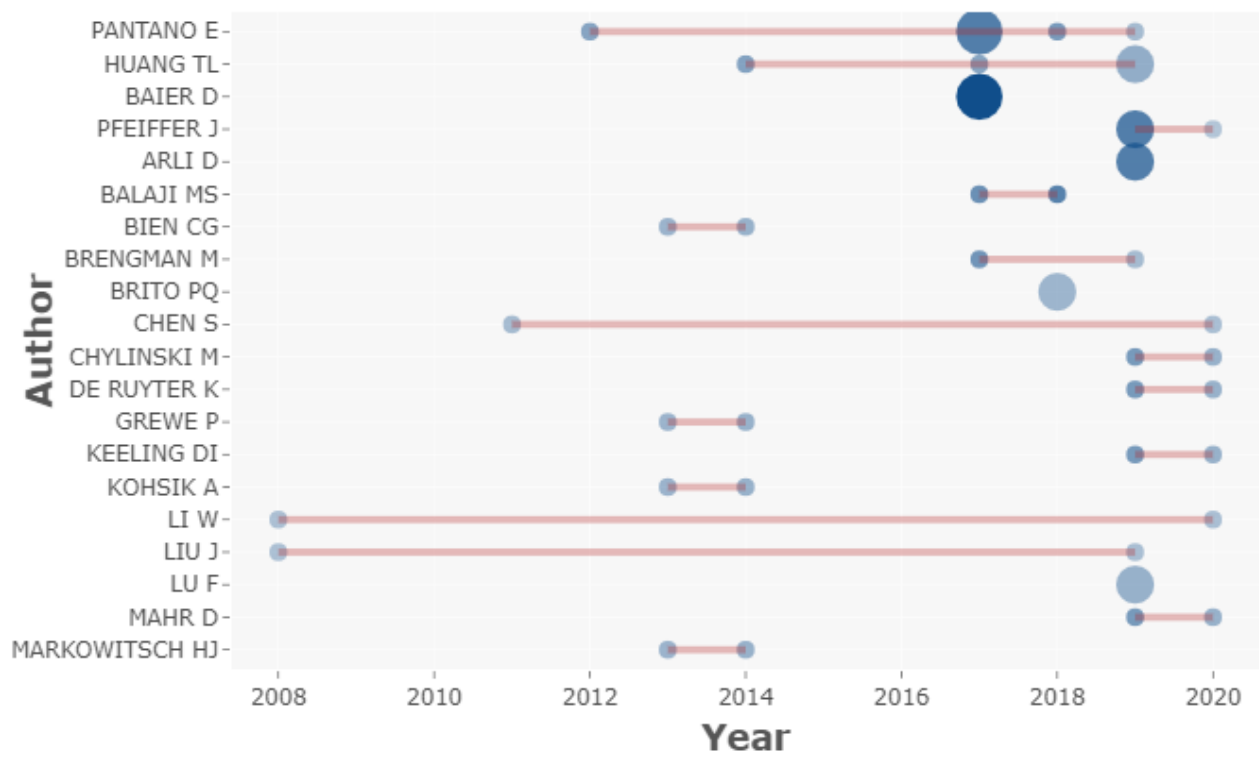

Fig 3: Top Authors Production over the years

In his study, Pantano E has examined the benefits of "Augmented Reality and Virtual Reality" in 
retail and has also proposed a theoretical framework for innovative and efficient stores. He has used data to map the correlations among variables and investigate the influence on consumers by employing the "Structural Equation Model (SEM)". The results indicated consumers are attracted and appealing towards the introduction of immersive technologies like augmented and virtual reality in traditional points of sales. (Pantano \& Servidio, 2012)

\begin{tabular}{|l|l|l|l|l|l|l|}
\hline (Author) & (H index) & $(\mathbf{G}$ index) & $\mathbf{( M ~ i n d e x )}$ & $\mathbf{( T C )}$ & $(\mathbf{N P})$ & (PY start) \\
\hline PANTANO E & 4 & 6 & 0.444 & 108 & 6 & 2012 \\
\hline HUANG TL & 3 & 4 & 0.429 & 62 & 4 & 2014 \\
\hline BAIER D & 2 & 3 & 0.5 & 71 & 3 & 2017 \\
\hline PFEIFFER J & 2 & 3 & 1 & 21 & 3 & 2019 \\
\hline ARLI D & 2 & 2 & 1 & 21 & 2 & 2019 \\
\hline BALAJI MS & 2 & 2 & 0.5 & 62 & 2 & 2017 \\
\hline BIEN CG & 2 & 2 & 0.25 & 42 & 2 & 2013 \\
\hline BRENGMAN M & 2 & 2 & 0.5 & 32 & 2 & 2017 \\
\hline BRITO PQ & 1 & 2 & 0.333 & 7 & 2 & 2018 \\
\hline
\end{tabular}

Table 2: Top 10 Author Impact

\subsection{Analysis on Distribution of Prime Research Countries}

Papers published in various regions can reflect the influence and importance of that country in the area of augmented and virtual reality in retail, to an extent. 38 countries have published between 1993-2020. As can be seen in Table 3 the top ten countries with the "maximum number of

\begin{tabular}{|l|l|}
\hline region & Freq \\
\hline CHINA & 96 \\
\hline USA & 85 \\
\hline UK & 71 \\
\hline GERMANY & 57 \\
\hline SOUTH KOREA & 37 \\
\hline AUSTRALIA & 28 \\
\hline FRANCE & 24 \\
\hline NETHERLANDS & 20 \\
\hline ITALY & 19 \\
\hline INDIA & 14 \\
\hline
\end{tabular}

Table 3: Top 10 Country Production Frequency

frequent collaboration between different countries, In Figure 4, it can be seen that countries with a higher number of documents have a darker shade than the ones with lower. Also, from the table and figure it can be observed that there has been a documents". Out of these, the 5 top countries with the maximum number of documents are: (i) "China", (ii) "the United States", (iii) "the United Kingdom", (iv) "Germany", and (v) "South Korea". However, in Table 3 we can see that the USA has the highest citations, 518 followed by the UK with the top five frequent collaboration between the USA and China, China and UK, Australia and China, Australia and UK, and Germany and UK. 


\section{Country Collaboration Map}

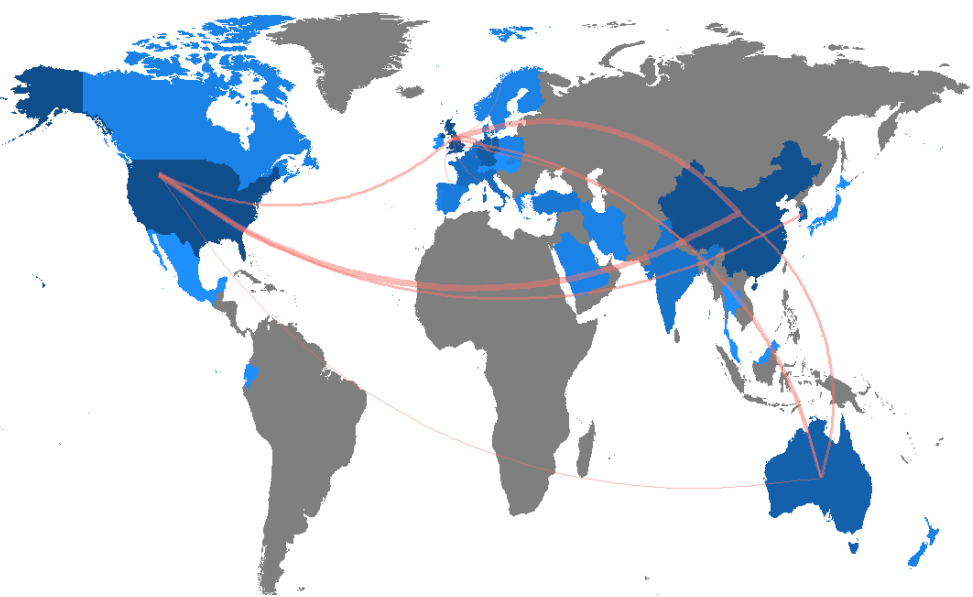

Fig 4: Country Collaboration Map

\begin{tabular}{|l|l|l|}
\hline From & To & Frequency \\
\hline USA & CHINA & 6 \\
\hline CHINA & UNITED KINGDOM & 5 \\
\hline AUSTRALIA & CHINA & 3 \\
\hline AUSTRALIA & UNITED KINGDOM & 3 \\
\hline GERMANY & UNITED KINGDOM & 3 \\
\hline
\end{tabular}

Table 4: Top 5 Country Collaboration with frequency

\subsection{Keywords Analysis}

Keywords analysis such as cluster analysis reflects the theme of the article in the study of augmented and virtual reality in retail in a concise way. The software package, Biblioshiny is used for the "Data mining and statistical analysis" of the frequently used keywords in the research paper. (Aria \& Cuccurullo, 2017)

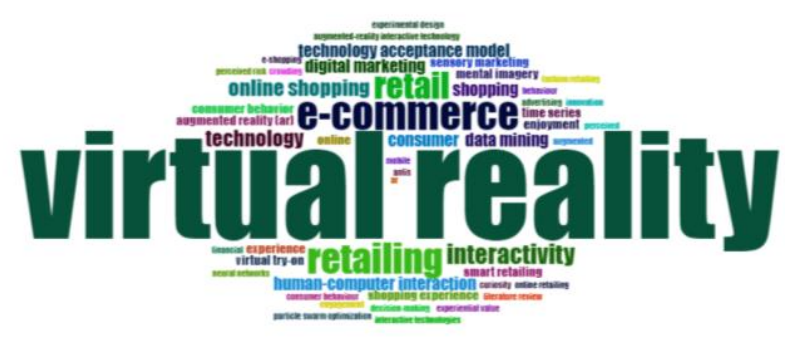

Fig 5: Word Cloud

Based on the Visualisation tool VOSViewer has been used for the Co-occurrence matrix which shows the link between research themes. The nodes' size indicates the frequency of keywords: the more frequently used the keyword is, the larger is the size of the node. The thickness of the line is directly related to the proximity of connections between two keywords, the thicker the line between two words is, closer is the relationship (Nicolas et al., 2019). Considering the keywords from the analysis of VOSViewer, 3 major clusters have been formed.

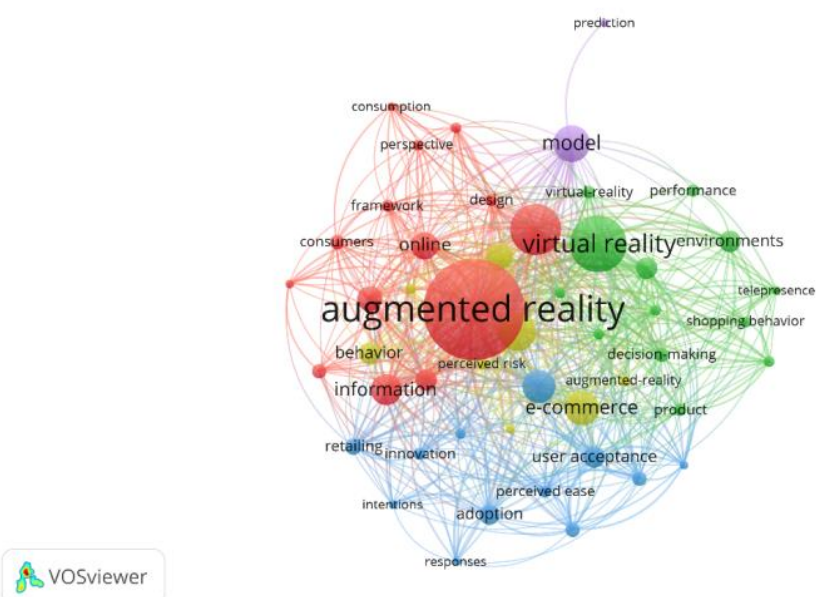

Fig 6: Co-occurrence Matrix

\section{(1) Adoption and Acceptance of AR/VR}

The "VR and AR" market in real-estate is expected to reach close to " $\$ 80$ billion", by 2025 . (i) Time savings, (ii) Global buying, and (iii) Selling, (iv) Tackling intangibility and (v) Narrowing the interest pool for buyers are amongst the key benefits of these technologies (Forbes, 2017). (Ullah et al., 2018), has employed 
the "Technology Acceptance Model (TAM)" to check AR/VR acceptance in real estate space. (Ullah et al., 2018) found that the sense of entertainment, playful attributes, and ability to do changes through Virtual and Augmented reality improved consumer satisfaction.

"Technology Acceptance Model (TAM)" and its key factors like convenience, attitude, behavioral intention, and usefulness are widely used to check consumer acceptance of advanced technology (Davis, 1989). (Pantano \& Gandini, 2017) has also considered technological characteristics like interactivity, aesthetics, information quality, and response time to support the study. It was found that consumers considered augmented reality as a powerful tool that can help them in making decisions. Virtual try-on enhanced their shopping experience and would substitute the physical trials by matching to the preferences as well.

\section{Published in 2018 by (Chandra S and Kumar KN)} in Journal of Electronic Commerce Research, uses a theoretical framework, "TechnologyOrganization-Environment (TOE)" to offer components that influence adoption intention of AR from organization's point of view. The model is tested on a sample of capable embracers from "India", "Singapore", and "the USA" and findings indicate factors like top management support, technology competence, consumer readiness, and comparative advantage as the determinants in the adoption of this technology. In the case of ecommerce, adoption of AR was negatively related to the age of the firm and positively related to higher/top management support, the readiness of consumers, and the level of competence of the organization. (Chandra \& Kumar, 2018).

\section{(2) Impact of Interactivity on Consumers}

Consumers engagement in case of shopping and brand activities has changed considerably as a result of Interactive technologies (Hoffman \& Novak, 1996). In the research by (Javornik, 2016) it saliently studies the characteristics of interactive technology and provides insight into the type of consumer response this technology incites, and gives an overview of some of the current advances of AR. The paper indicates that in the initial phase with technology, AR has more hedonic than the utilitarian effect on consumer experience and this affective component has a strong role to play. It was found that most AR apps are location-specific and this makes them highly relevant for retail. Also, Privacy concerns are considered as less intrusive in the case of AR technology present on smart devices.

(Vannucci \& Pantano, 2019) indicates that investing in digital touchpoints are influential in retail and digital technology makes the process of locating, product comparison, and making payments faster, without wasting time standing in queue.

AR positively impacts purchase intention and "word of mouth" (Hilken, 2017) and "word of mouth (WOM) intentions" (Hilken, 2017). Utilitarian and hedonic value, spatial presence, and ease of decision making mediated the impact of AR on patronage intentions (Hilken, 2017). Customer loyalty, shopping effectiveness, and spending more time with the retailer was mediated in a positive direction by the use of $A R$ and negative direction by perceived risk. The influence of smart customer experience on behavioural intentions, WOM, stickiness to the retailer (spend more time with the retailer), and shopping effectiveness was mediated in a positive direction by satisfaction and in a negative direction by perceived risk (Roy et al., 2017).

\section{(3) Performance and Information Control}

While users of Augmented reality prefer receiving rich information that is relevant to the context, the importance of protection of privacy and information is also increasing (Olsson et al., 2013). (Poushneh, 2018) used Equity Theory which indicates that "Augmentation quality" and "user's control of access to personal information" hold equal importance in shaping user's attitudes towards AR.

In the case of physical retail, the AR gamification feature results in a compelling and arousal experience (Poncin \& Ben Mimoun, 2014). The use of Mobile AR apps was perceived to add value to retail stores as it offered product information and demonstration capabilities (Dacko, 2017). (Baytar, Chung, and Shin) used the S-O-R model in his paper as a theoretical framework which indicated that AR will not replace the physical stores but will supplement them. Also, for consumers with a certain level of telepresence, AR proves to be instrumental in driving sales by building a positive attitude towards products 
The study by (Lu \& Smith, 2010) shows that in the case of e-commerce AR provides direct experience and better information to online customers, as it combines information from physical environment information with the virtual environment. Thus, helps customers in making a better and informed purchase decision.

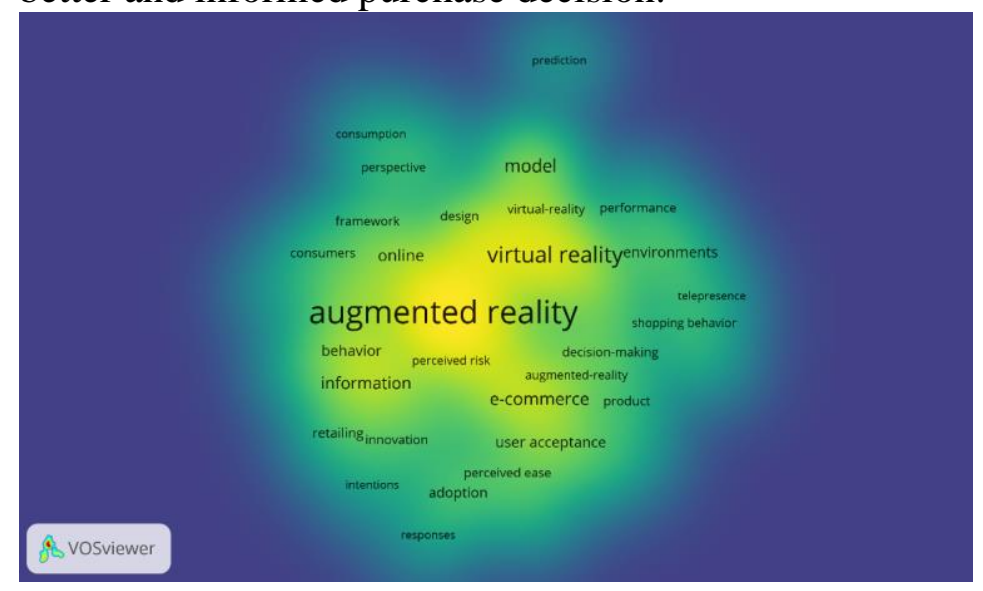

Fig 7: Heat Map

\section{Discussion and Conclusion}

Based on existing works of literature, it can be inferred that the study of AR/VR in retail though started early is yet in the evolving phase. In future, further research needs to be done in this which will encompass a greater number of documents to focus on the developing trends in retail and changing consumer preferences due to the adoption of AR/VR technology.

Based on Web of Science database, documents in the field of "Augmented and Virtual Reality" in Retail from 1993-2020 were fetched, and "VOS viewer" and "Biblioshiny software packages" were employed for "data mining and data analysis". AR/VR in retail research shows the below mentioned characteristics:

(1) As inferred from the publication trend, the number of documents on $\mathrm{AR} / \mathrm{VR}$ in retail continues to grow with a bit of fluctuation in between, The growth has been maximum in It can be divided into 2 zones - (i) low exploration and (ii) developmental period. Prior 2010, the rise in the published-articles was slow-moving. The study on AR/VR technology in retail was in early stage, indicating that the importance of Augmented and Virtual Reality had not caught most scholars' attention. However, post-2010, the articles published in this period rose over time.

(2) Regarding the research power in this field, China, the USA, UK play an important role. Also, there has been a frequent collaboration between these countries.

(3) Based on the frequent keywords used in the field of AR/VR in retail, co-occurrence matrix, and word cloud were created. The most frequent keywords included- virtual reality, adoption, interactivity, performance. On further analysis, three major clusters were formed which encompassed the keywords. The three major clusters are - Adoption and Acceptance of AR/VR, Performance and Information Control, Impact of Interactivity on Consumers.

(4) Researchers have used various frameworks like "Technology-Organization-Environment" (TOE), "Technology Acceptance Model" (TAM), and others to study the adoption and acceptance of this technology and found that retailers, as well as consumers, have a high affinity towards this technology. The interactivity increases the consumer's learning about the product and positively impacts purchase intention, word of mouth. However, augmentation quality and privacy of user's information play a crucial role in the user's acceptance of this technology.

\section{References}

[1] Albort-Morant, G., \& Ribeiro-Soriano, D. (2016a). A bibliometric analysis of international impact of business incubators. Journal of Business Research, 69(5), 17751779. https://doi.org/10.1016/j.jbusres.2015.10.05 4

[2] Albort-Morant, G., \& Ribeiro-Soriano, D. (2016b). A bibliometric analysis of international impact of business incubators. Journal of Business Research, 69(5), 17751779 .

https://doi.org/10.1016/j.jbusres.2015.10.05 4

[3] Aria, M., \& Cuccurullo, C. (2017). bibliometrix: An R-tool for comprehensive science mapping analysis. Journal of Informetrics, 11(4), 959-975. https://doi.org/10.1016/J.JOI.2017.08.007

[4] Azuma, R., Baillot, Y., Behringer, R., Feiner, S., Julier, S., \& MacIntyre, B. (2001). Recent advances in augmented reality. IEEE Computer Graphics and 
Applications, 21(6),

34-47. https://doi.org/10.1109/38.963459

[5] Baytar, F., Chung, T., \& Shin, E. (N.D.). Evaluating Garments In Augmented Reality When Shopping Online. In Journal Of Fashion Marketing And Management. Emerald Group Publishing Ltd. Https://Doi.Org/10.1108/Jfmm-05-20180077

[6] Bornmann, L., \& Daniel, H. D. (2008). What do citation counts measure? A review of studies on citing behavior. Journal of Documentation, 64(1), 45-80. https://doi.org/10.1108/0022041081084415 0

[7] Broadus, R. N. (1987). Early approaches to bibliometrics. Journal of the American Society for Information Science, 38(2), 127-129. https://doi.org/10.1002/(SICI)10974571(198703)38:2<127::AID-ASI6>3.0.CO;2-K

[8] Chandra, S., \& Kumar, K. N. (2018). Exploring Factors Influencing Organizational Adoption Of Augmented Reality In E-Commerce: Empirical Analysis Using Technology-OrganizationEnvironment Model. In Journal Of Electronic Commerce Research (Vol. 19, Issue 3, Pp. 237-265). California State Univ.

[9] Council Post: Eight Ways Virtual And Augmented Reality Are Changing The Real Estate Industry. (n.d.). Retrieved September 15, 2020, from https://www.forbes.com/sites/forbesrealestat ecouncil/2017/07/14/eight-ways-virtual-andaugmented-reality-are-changing-the-realestate-industry/\#d5176a65a3f5

[10] Cruz, E., Orts-Escolano, S., GomezDonoso, F., Rizo, C., Rangel, J. C., Mora, H., \& Cazorla, M. (2019). An augmented reality application for improving shopping experience in large retail stores. VIRTUAL REALITY, 23(3, SI), 281-291. https://doi.org/10.1007/s10055-018-0338-3

[11] Cycles, T. text provides general information S. assumes no liability for the information given being complete or correct D. to varying update, \& Text, S. C. D. M. up-to-D. D. T. R. in the. (n.d.). Topic: Retail market worldwide. Statista. Retrieved September 15, 2020, from https://www.statista.com/topics/5922/retail-marketworldwide/

[12] Dacko, S. G. (2017). Enabling smart retail settings via mobile augmented reality shopping apps. In TECHNOLOGICAL FORECASTING AND SOCIAL CHANGE (Vol. 124, pp. 243-256). ELSEVIER SCIENCE INC. https://doi.org/10.1016/j.techfore.2016.09.0 32

[13] Davis, F. D. (1989). Perceived Usefulness, Perceived Ease of Use, and User Acceptance of Information Technology. MIS Quarterly, 13(3), 319-340. JSTOR. https://doi.org/10.2307/249008

[14] Exploring factors influencing organizational adoption of augmented reality in e-commerce: Empirical analysis using technology-organization-environment model. (n.d.). Retrieved September 15, 2020, from https://www.researchgate.net/publication/32 7249338_Exploring_factors_influencing_or ganizational_adoption_of_augmented_realit y_in_ecommerce_Empirical_analysis_using_techn ology-organization-environment_model

[15] Grewal, D., Roggeveen, A. L., \& Nordfält, J. (2017). The Future of Retailing. Journal of Retailing, 93(1), 1-6. https://doi.org/10.1016/j.jretai.2016.12.008

[16] Hilken, T., de Ruyter, K., Chylinski, M., Mahr, D., \& Keeling, D. I. (2017). Augmenting the eye of the beholder: Exploring the strategic potential of augmented reality to enhance online service experiences. Journal of the Academy of Marketing Science, 45(6), 884-905. https://doi.org/10.1007/s11747-017-0541-x

[17] Hoffman, D. L., \& Novak, T. P. (1996). Marketing in Hypermedia ComputerMediated Environments: Conceptual Foundations. Journal of Marketing, 60(3), 50-68. JSTOR. https://doi.org/10.2307/1251841 
[18] Hopping, D. (2000). Technology in retail. Technology in Society, 22(1), 63-74. https://doi.org/10.1016/S0160-791X(99)00042-1

[19] Javornik, A. (2016). Augmented reality: Research agenda for studying the impact of its media characteristics on consumer behaviour. In JOURNAL OF RETAILING AND CONSUMER SERVICES (Vol. 30, pp. 252-261). ELSEVIER SCI LTD. https://doi.org/10.1016/j.jretconser.2016.02.004

[20] Lu, Y., \& Smith, S. (2010). Augmented Reality E-Commerce System: A Case Study. Journal of Computing and Information Science in Engineering, 10(2), 021005. https://doi.org/10.1115/1.3385795

[21] Nicolas, C., Valenzuela-fernandez, L., \& Merigó, J. M. (2019). Mapping retailing research with bibliometric indicators. Journal of Promotion Management, 0(0), 117. https://doi.org/10.1080/10496491.2019.1585579

[22] Olsson, T., Lagerstam, E., Karkkainen, T., \& Vaananen-Vainio-Mattila, K. (2013). Expected user experience of mobile augmented reality services: A user study in the context of shopping centres. In PERSONAL AND UBIQUITOUS COMPUTING (Vol. 17, Issues 2, SI, pp. 287-304). SPRINGER LONDON LTD. https://doi.org/10.1007/s00779-011-0494-X

[23] Pantano, E. (2016). Engaging consumer through the storefront: Evidences from integrating interactive technologies. Journal of Retailing and Consumer Services, 28, 149-154.

https://doi.org/10.1016/j.jretconser.2015.09.007

[24] Pantano, E., Priporas, C. V., Sorace, S., \& Iazzolino, G. (2017). Does innovationorientation lead to retail industry growth? Empirical evidence from patent analysis. Journal of Retailing and Consumer Services, 34, 88-94. https://doi.org/10.1016/j.jretconser.2016.10. 001

[25] Pantano, E., \& Servidio, R. (2012). Modeling innovative points of sales through virtual and immersive technologies. Journal of Retailing and Consumer Services, 19(3), 279-286.

https://doi.org/10.1016/j.jretconser.2012.02.002
[26] Poncin, I., \& Ben Mimoun, M. S. (2014). The impactof "e-atmospherics" on physical stores. In JOURNAL OF RETAILING AND CONSUMER SERVICES (Vol. 21, Issue 5, pp. 851-859). ELSEVIER SCI LTD.

https://doi.org/10.1016/j.jretconser.2014.02.013

[27] Poushneh, A. (2018). Augmented reality in retail: A trade-off between user's control of access to personal information and augmentation quality. In JOURNAL OF RETAILING AND CONSUMER SERVICES (Vol. 41, pp. 169-176). ELSEVIER SCI https://doi.org/10.1016/j.jretconser.2017.12. 010

[28] Reeves Martin, \& Deimler Mike. (2011). Adaptability: The New Competitive Advantage. https://hbr.org/2011/07/adaptabilitythe-new-competitive-advantage

[29] Roy, S. K., Balaji, M. S., Sadeque, S., Nguyen, B., \& Melewar, T. C. (2017). Constituents and consequences of smart customer experience in retailing. In TECHNOLOGICAL FORECASTING AND SOCIAL CHANGE (Vol. 124, pp. 257-270). ELSEVIER SCIENCE INC. https://doi.org/10.1016/j.techfore.2016.09.0 22

[30] Smith, L. C. (1981). Citation analysis. Library Trends, 30(1), 83-106.

[31] Suh, K., \& Lee, Y. (2005). The effects of virtual reality on consumer learning: An empirical investigation. In MIS QUARTERLY (Vol. 29, Issue 4, pp. 673697). SOC INFORM MANAGE-MIS RES CENT.

[32] Thakur, R., \& Srivastava, M. (2014). Adoption readiness, personal innovativeness, perceived risk and usage intention across customer groups for mobile payment services in India. In INTERNET RESEARCH (Vol. 24, Issue 3, pp. 369392). EMERALD GROUP PUBLISHING LTD. https://doi.org/10.1108/IntR-12-20120244

[33] Ullah, F., Sepasgozar, S. M. E., \& Wang, C. (2018). A systematic review of smart real estate technology: Drivers of, and barriers 
to, the use of digital disruptive technologies and online platforms. In Sustainability (Switzerland) (Vol. 10, Issue 9, p. 3142).

MDPI AG. https://doi.org/10.3390/su10093142

[34] Vannucci, V., \& Pantano, E. (2019). Digital or human touchpoints? Insights from consumer-facing in-store services. Information Technology \& People, 33(1), 296-310. https://doi.org/10.1108/ITP-022018-0113 